REVISTA CRIOULA N ${ }^{\circ} 21-1^{\circ}$ SEMESTRE/2018

\title{
A IMAGEM OFICIAL DO ESTADO NOVO PORTUGUÊS E SUAS DESCONSTRUÇÕES
}

\section{The official image of the Portuguese New State and ITS DECONSTRUCTIONS}

Márcio Aurélio Recchia ${ }^{1}$

DOI 10.11606/issn.1981-7169.crioula.2018.143180

RESUMO: Neste artigo, pretendo apresentar algumas reflexões acerca da desconstrução da imagem oficial do Estado Novo português através de dois objetos de estudo: o romance O ano da morte de Ricardo Reis (1984), de José Saramago, e o filme Fantasia Lusitana (2010), de João Canijo. No romance, este expediente ocorre, sobretudo, por meio do narrador, ao passo que, no documentário, o mesmo se dá pela presença de certos estrangeiros que utilizaram Lisboa como rota de fuga dos nazistas durante a Segunda Guerra Mundial.

ABSTRACT: In this article, I aim to present some reflections about the deconstruction of the official image of the Portuguese New State through two objects of study: the novel

${ }^{1}$ Mestrando em Letras na Área de Estudos Comparados de Literaturas de Língua Portuguesa, Departamento de Línguas Clássicas e Vernáculas da Faculdade de Filosofia, Letras e Ciências Humanas pela USP. 
The year of the death of Ricardo Reis (1984), by José Saramago, and the film Fantasia Lusitana (2010), by João Canijo. In the novel, this expedient occurs, especially, through the narrator, whereas in the documentary, it happens through the presence of certain foreigners who used Lisbon as an escape route from the Nazi during World War II.

PALAVRAS-CHAVE: Salazarismo; Estado Novo; Propaganda; Segunda Guerra Mundial; Refugiados.

KEYWORDS: Salazarism; New State; Propaganda; World War II; Refugees.

\section{INTRODUÇÃO}

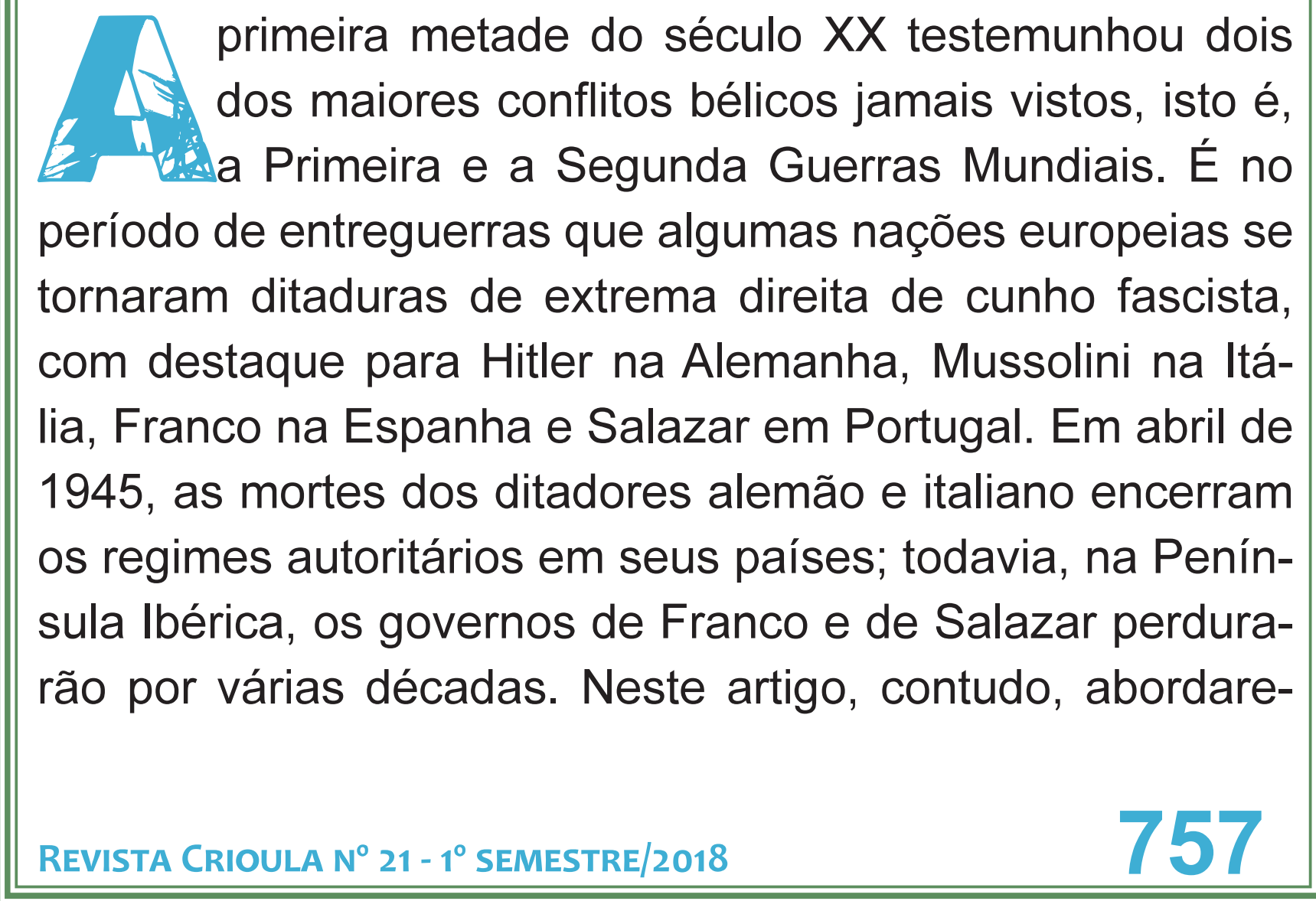




\section{REVISTA CRIOULA N ${ }^{\circ} 21-1^{\circ}$ SEMESTRE/2018}

mos apenas o caso português.

A longa duração da ditadura de Salazar está relacionada à eficiência da propaganda política veiculada pelo governo, que, assente no discurso paternalista do ditador, procurou controlar as informações divulgadas pelos meios de comunicação. Duas obras, o romance $O$ ano da morte de Ricardo Reis (1984), de José Saramago, e o filme Fantasia Lusitana (2010), do cineasta português João Canijo, procuram desconstruir essa propaganda. $\mathrm{O}$ objetivo desse artigo é analisar de que modo, em cada uma delas, se dá essa desconstrução.

Apesar de essas obras terem sido realizadas em suportes diversos, é importante destacar que é possível estabelecer um diálogo interdisciplinar entre elas. Sérgio Sousa, ao refletir sobre as relações intersemióticas entre o cinema e a literatura, ressalta que essas duas artes mantêm entre si um elevado grau de afinidade "por partilharem de uma matéria de expressão comum (o signo verbal); por consistirem ambas na representação de uma sucessividade de acontecimentos distribuídos num tempo-espaço e por disporem de estruturas enunciativas (dimensão narrativa)" (SOUSA, 2001, p. 15). Levando-se em conta o alto grau de afinidade existente entre literatura e cinema, mesmo quando não se trata de adaptação, convém destacar que as obras em questão têm ainda em comum a afinidade temática, uma vez que ambas abordam criticamente os anos de consoli- 


\section{REVISTA CRIOULA N ${ }^{\circ} 21$ - $1^{\circ}$ SEMESTRE/2018}

dação do Estado Novo, a partir da desconstrução da propaganda salazarista.

A respeito do contexto histórico, o professor Luís Reis Torgal afirma que:

\section{O Estado Novo sempre se apresentou a si próprio} como uma forma "original» de regime autoritário, procurando distanciar-se, desde o início de sua formação e devido a sua alegada matriz católica, do "totalitarismo» [...]. Assim, essa imagem de marca de um Estado forte, intervencionista, autoritário mas paternal, anticomunista e contrário à democracia pluripartidária, mas defensor de uma «democracia social» de tipo corporativo, acabou por enlear e até entusiasmar políticos de vários países e de diversas tendências. (TORGAL, 2011, p. 64)

O recorte temporal das duas obras não coincide totalmente, já que o enredo do romance se desenvolve, principalmente, no ano de 1936, ao passo que os excertos de propaganda utilizados na realização do documentário abrangem um período posterior mais vasto (final dos anos 1930 até 1959). Contudo, além de desconstruírem os veículos de divulgação da ideologia salazarista, acabam por abordar o cenário bélico vivido na Europa nas décadas de 1930 e 1940. 
Em O ano da morte de Ricardo Reis, pelo recorte temporal adotado, apenas o início da Guerra Civil Espanhola e os prenúncios da Segunda Guerra Mundial estão focalizados na narrativa. Já no caso de Fantasia Lusitana, o conflito mundial em si é que ganha proeminência.

O romance tem como protagonista Ricardo Reis, personagem criado a partir do heterônimo pessoano que retorna a Portugal após saber da morte de Pessoa, ocorrida em 30 de novembro de 1935. Segundo correspondência deixada pelo poeta de Orpheu a Casais Monteiro, Reis teria se exilado voluntariamente no Rio de Janeiro em 1919, após uma tentativa fracassada de restauração da monarquia em seu país.

O enredo é contado por uma instância narrativa onisciente e irônica, que se torna elemento central na desconstrução da propaganda estatal. Além do narrador, destacamos os personagens Fernando Pessoa, Lídia e seu irmão, o marinheiro Daniel, que, de certa forma, questionam ou combatem o regime político em que estão inseridos, contribuindo com a desestabilização da imagem oficial criada pelo Estado Novo.

Com relação ao documentário, a presença de refugiados estrangeiros em Portugal durante a Segunda Guerra Mundial faz o contraponto com a imagem da propaganda veiculada pelo regime. A película recupera a memória de três intelectuais que passaram por Lisboa em 1940: o mé- 
REVISTA CRIOULA N ${ }^{\circ} 21-1^{\circ}$ SEMESTRE/2018

dico e escritor judeu-alemão Alfred Döblin; a dramaturga alemã Erika Mann; o aviador e escritor francês Antoine de Saint-Exupéry.

Canijo adota uma estratégia de desconstrução da aparente paz portuguesa ao sobrepor o relato dessas três testemunhas às imagens que foram originalmente utilizadas pela propaganda para fortalecer o regime. Esta sobreposição se dá por meio da voz off de atores cujos idiomas são os mesmos falados pelos refugiados. A justaposição, quase sempre contrastante, entre o que o espectador vê e ouve produz um efeito crítico e irônico, enfraquecendo a propaganda salazarista.

Além do recurso da inclusão das memórias dos três refugiados, há também a presença da voz off de Salazar lendo trechos de seus discursos. Esta voz, mansa algumas vezes e empolada noutras, aplicada às imagens panfletárias da época, acaba por ridicularizar e contrapor a propaganda, embora, em sua origem, a maioria deste material tivesse a intenção de demostrar a nação como um verdadeiro "oásis de paz".

Esta técnica evidencia que Portugal é um país pobre e vulnerável perante o potencial bélico circundante, ou seja, uma realidade bem diversa daquela apregoada pelo regime. Ademais, há o fato de que os refugiados se encontravam em Portugal provisoriamente, e, por isso, não estavam influenciados diretamente pela propaganda estatal. São várias as 
estratégias de desconstrução da propaganda salazarista empregadas em ambos os textos. A partir de agora, passaremos a analisar algumas delas.

\section{O USO DA IRONIA}

O narrador de $\mathrm{O}$ ano da morte de Ricardo Reis é essencialmente irônico e faz uso desse expediente para enfraquecer e ridicularizar não apenas a ideologia salazarista, mas também a imagem do próprio ditador. É importante ressaltar que o Estado Novo foi oficialmente criado com a aprovação da Constituição de 1933. Segundo o historiador Fernando Rosas, em seu período de consolidação,

[...] o Estado Novo, à semelhança de outros regimes fascistas ou fascizantes da Europa, alimentou e procurou executar, a partir de órgãos do Estado especialmente criados para o efeito, um projecto totalizante de reeducação dos «espíritos», de criação de um novo tipo de portuguesas e de portugueses regenerados pelo ideário genuinamente nacional de que o regime se considerava portador. (ROSAS, 2001, p. 1032)

Há uma passagem no romance em que Fernando Pessoa se encontra com o protagonista e ambos conver- 


\title{
REVISTA CRIOULA N ${ }^{\circ} 21$ - $1^{\circ}$ SEMESTRE/2018
}

sam sobre Salazar. Recém-chegado ao país, Reis pergunta a Pessoa sobre o ditador:

\begin{abstract}
Diga-me, Fernando, quem é, que é este Salazar que nos calhou em sorte, É o ditador português, o protector, o pai, o professor, o poder manso, um quarto de sacristão, um quarto de sibila, um quarto de Sebastião, um quarto de Sidónio, o mais apropriado possível aos nossos hábitos $\mathrm{e}$ índole, Alguns pês e quatro esses, Foi coincidência, não pense que andei a procurar palavras que principiassem pela mesma letra (SARAMAGO, 1994 , p. 278 - grifos meus)
\end{abstract}

A reputação do estadista é des/re-construída de forma habilidosa por Fernando Pessoa. Ele define Salazar de modo a evidenciar a imagem desejada pelo governo, isto é, protetor, pai, professor e poder manso, porém, o faz diretamente, sem os subterfúgios usados pela propaganda. Ao classificá-lo como sacristão, sibila, Sebastião e Sidónio, isto é, figuras míticas, históricas e/ou religiosas, Salazar é envolto numa aura mística e profética, despontando, para muitos, como figura promissora naqueles anos iniciais de estabelecimento do Estado Novo. Por outro lado, graças ao distanciamento temporal de quase cinquenta anos entre o tempo diegético e a publicação da obra, constatamos que essa promessa não se cumpriu, revelando a quebra da ex- 
pectativa dos que viam em Salazar um salvador da pátria.

Em outra passagem acerca de datas envolvendo o ditador português temos:

Agora se festejaram duas datas, a primeira que foi do aparecimento do professor António de Oliveira Salazar na vida pública, há oito anos, parece que ainda foi ontem, como o tempo passa, para salvar o seu e o nosso país do abismo, para o restaurar, para lhe impor uma nova doutrina, fé, entusiasmo e confiança no futuro, são palavras do periódico, e a outra data que também diz respeito ao mesmo senhor professor, sucesso de mais íntima alegria, sua e nossa, que foi ter completado, logo no dia a seguir, quarenta e sete anos de idade, nasceu no ano em que Hitler veio ao mundo e com pouca diferença de dias, vejam lá o que são coincidências, dois importantes homens públicos (SARAMAGO, 1994, p. 298-299)

Como se sabe, Estados autoritários sempre incentivaram e promoveram as comemorações de efemérides a fim de fomentar aquilo que interessava a cada um deles. No caso português, as duas datas exploradas no excerto em destaque se referem ao aniversário do surgimento de Salazar na vida pública como Ministro das Finanças (1928) 
REVISTA CRIOULA N ${ }^{\circ} 21-1^{\circ}$ SEMESTRE/2018

e posteriormente como Presidente do Ministério (1932) e ao seu natalício (28/04/1889). Porém, a forma adotada pela instância narrativa ao abordar esses assuntos ridiculariza a imagem do estadista.

Primeiramente, essa estratégia patenteia aquilo que era divulgado pela imprensa portuguesa de então, mas o faz num contexto diverso, para o leitor que não está mais sob a influência salazarista. Ler que o debuto político de Salazar serviu para que ele estabilizasse o país é efetivamente irônico, graças ao distanciamento histórico vivido pelo leitor do romance. Sabe-se que essa promessa não se cumpriu, que Salazar acabou se convertendo em um ditador autoritário que permaneceu no poder por 36 anos e que aquelas palavras não passavam da elaboração de uma imagem idealizada do estadista criada pela propaganda. O próprio narrador se exime de compartilhar desse pensamento ao reforçar que aquelas eram palavras do periódico e não a sua opinião.

Com relação ao nascimento de Salazar, a ironia está no fato de ser próximo ao natalício de Hitler, ambos nascidos em abril de 1889, e de esta coincidência ser salientada pelo narrador. Chamar os dois ditadores de "importantes homens públicos" satiriza mais uma vez a imagem de Salazar, visto que a referência atual que temos do ditador alemão remete ao Holocausto judeu e aos campos de concentração e extermínio. Por mais que o narrador use um tom de deferência para com Salazar, tratando-o por "senhor professor", ou lhe atribua o mérito por Portugal ter conseguido equilibrar suas 
finanças, é notório que o que está por trás é a denúncia da construção da imagem do chefe da nação pela imprensa portuguesa, em prol da ideologia do regime.

Aproximar Salazar de Hitler é, de certa forma, desmoralizá-lo. É recordar que Salazar também criou instrumentos de perseguição contra quem contestasse o Estado Novo, tais como a polícia política (PVDE/PIDE), que utilizava tortura contra seus inimigos. É lembrar que ele criou a colônia penal do Tarrafal (Cabo Verde) naquele ano de 1936 - e que viria a se converter em um campo de concentração contra presos políticos. Assim, a desconstrução da imagem de Salazar ao aproximá-lo de Hitler só é possível através do distanciamento temporal entre o presente diegético (1936) e a publicação do romance (1984), espaçamento necessário para que ocorra essa ironia.

Com relação a Fantasia Lusitana, gostaríamos de analisar um excerto que também serve para ridicularizar a figura do Presidente da República, Oscar Carmona. As cenas exibidas são as dos festejos do oitavo centenário da fundação de Portugal em 1940, nas quais Carmona passeia por entre a multidão, recebendo uma chuva de flores (FANTASIA LUSITANA, 2010, 4:13). Ao mesmo tempo em que essas imagens são exibidas, o espectador ouve a voz off de Salazar lendo um de seus discursos, no qual ele descreve a essência dos portugueses:

Aquelas qualidades que se revelaram e fixaram e 
fazem de nós o que somos e não outros; aquela doçura de sentimentos, aquela modéstia, aquele espírito de humanidade, tão raro hoje no mundo; aquela parte de espiritualidade que, malgrado tudo que a combate, inspira ainda a vida portuguesa [...] (FANTASIA LUSITANA, 2010, 4:104:29 - grifos meus)

Ao definir a natureza do povo português, Salazar acaba por listar várias características positivas idealizadas. A construção dessa imagem está em consonância com as ideias nacionalistas propagadas pelo Estado Novo, sobretudo nesses primeiros anos de consolidação do governo. Entretanto, a montagem do documentário proporciona o sincronismo entre a imagem e o som, isto é, ao mesmo tempo em que o espectador vê Carmona beijando um bebê (Fig. 1), ele ouve a voz de Salazar enunciando "aquela doçura de sentimentos", referindo-se à alma portuguesa.

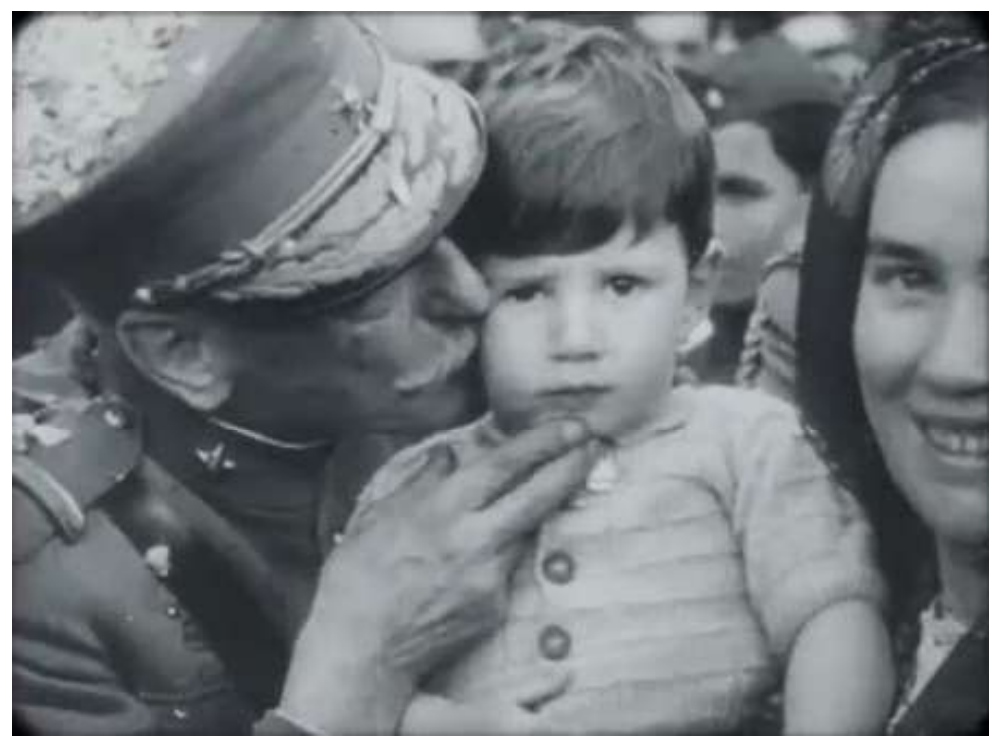

Figura 1 
Esta simultaneidade gerada pela montagem ratifica 0 que é dito pela voz do ditador, porém, a imagem alude ao estereótipo do político que, em períodos de eleição, anda por entre o povo, distribui abraços e beija criancinhas para ganhar votos, gerando uma imagem caricata e risível do Presidente e, por extensão, do próprio Salazar, que dá voz à cena. Além disso, há o contraste entre a imagem viril do militar, com seu uniforme e suas divisas, e o beijo dado em uma criança, que remete à ternura e à delicadeza, ou seja, à "doçura de sentimentos".

\section{O CHOQUE ENTRE REALIDADES COEXISTENTES}

Outra característica presente em ambas as obras é causar o choque das realidades vividas no Portugal de Salazar e no resto da Europa. No excerto a seguir, o narrador saramaguiano contrapõe os universos paralelos coexistentes em Portugal e na Espanha:

[...] não deveremos atribuir significado especial ao facto de a população de Badajoz se ter armado para resistir ao assalto iminente, ou atribuamos-Ihe apenas significado bastante para podermos admiti-lo àquela discussão sobre o que seja ou não seja o povo. [...] aqui armaram-se homens, mulheres e crianças, armaram-se de espingardas, de espadas, de mocas, de foices, 
de revólveres, de punhais, de cacetes, deitaram mão ao que havia, talvez por ser esta a maneira de armar-se o povo [...].

A onda cresce e rola. Em Portugal afluem as inscrições de voluntários para a Mocidade Portuguesa, são jovens patriotas que não quiseram esperar pela obrigatoriedade que há-de vir, eles por sua esperançosa mão, em letra escolar, sob o benévolo olhar da paternidade, firmaram a carta, e por seu firme pé a levam ao correio, ou trémulos de cívica comoção a entregam ao porteiro do ministério da Educação Nacional (SARAMAGO, 1994, p. 376-377 - grifos meus)

Ao analisarmos o trecho acima, notamos que cada um dos parágrafos aborda situações distintas. No primeiro, o enfoque recai sobre a população de Badajoz, cidade espanhola que se manteve resistente ao ataque dos nacionalistas. Vemos que o povo, indistintamente, lança mão de vários tipos de armas, muitas delas rudimentares, para defender a sua cidade contra o ataque franquista. Por outro lado, o segundo parágrafo discorre acerca de jovens lusitanos que, voluntariamente, aderem à Mocidade Portuguesa, uma organização criada naquele ano de 1936 com a finalidade de incutir na mente juvenil os valores do Estado Novo, promover a disciplina militar e incentivar o nacionalismo.

Ambos os parágrafos descrevem acontecimentos di- 
ferentes ocorrendo concomitantemente nas duas nações. A estratégia narrativa mostra um paralelismo que se dá por meio do uso de partes do corpo com fins muito destoantes. Enquanto os espanhóis de Badajoz utilizam suas mãos para pegar em armas e defender sua cidade da sanha franquista,os moços portugueses usam suas mãos para assinar os formulários de afiliação à organização juvenil de cunho fascista e seus pés para irem até os correios expedir suas vinculações. Em suma, enquanto a população de Badajoz se defende de Franco, os jovens portugueses apoiam e integram a organização de Salazar.

Da mesma maneira, a montagem de Fantasia Lusitana traz uma sequência de imagens que evidencia as realidades contrastantes em Portugal e na Europa em guerra. Há um trecho em que o jornalista Fernando Pessa, que trabalhava na BBC de Londres durante a guerra, explica o que eram as Blitz (abreviação da palavra alemã Blitzkrieg a partir dos $7 \mathrm{~m} 10 \mathrm{~s}$ ), ou seja, ataques aéreos relâmpagos. Este excerto exibe cenas de aviões lançando bombas, prédios e casas destruídos, pessoas correndo em busca de abrigo e, por fim, o desespero no rosto dos sobreviventes. As cenas finais dessa sequência são fortes, pois focalizam mulheres desconsoladas, um homem cego que caminha sozinho com duas bengalas por uma rua destruída, e imagens de mães e filhos que, com semblantes tristes, trocam beijos e afagos (Fig. 2).

O áudio presente nessas derradeiras cenas consis- 
te em ruídos de sirenes, em burburinho de vozes infantis e em uma música alta com ritmos regulares, cujo tom vai aumentando, gerando tensão e ansiedade. Abruptamente, aos $9 \mathrm{~m} 08 \mathrm{~s}$, há um corte nesta sequência e, num contraste brusco de imagens, o espectador se vê diante de uma cena festiva, filmada num acampamento da Mocidade Portuguesa, e passa a visualizar e ouvir um adolescente que canta uma música folclórica portuguesa, seguido de um coro de vozes masculinas (Fig. 3), o que causa um impacto muito grande. Isso se dá porque ocorre a quebra repentina da sequência anterior, fazendo com que a fantasia vivida em Portugal invada a sequência de acontecimentos dramáticos gerados pela guerra.

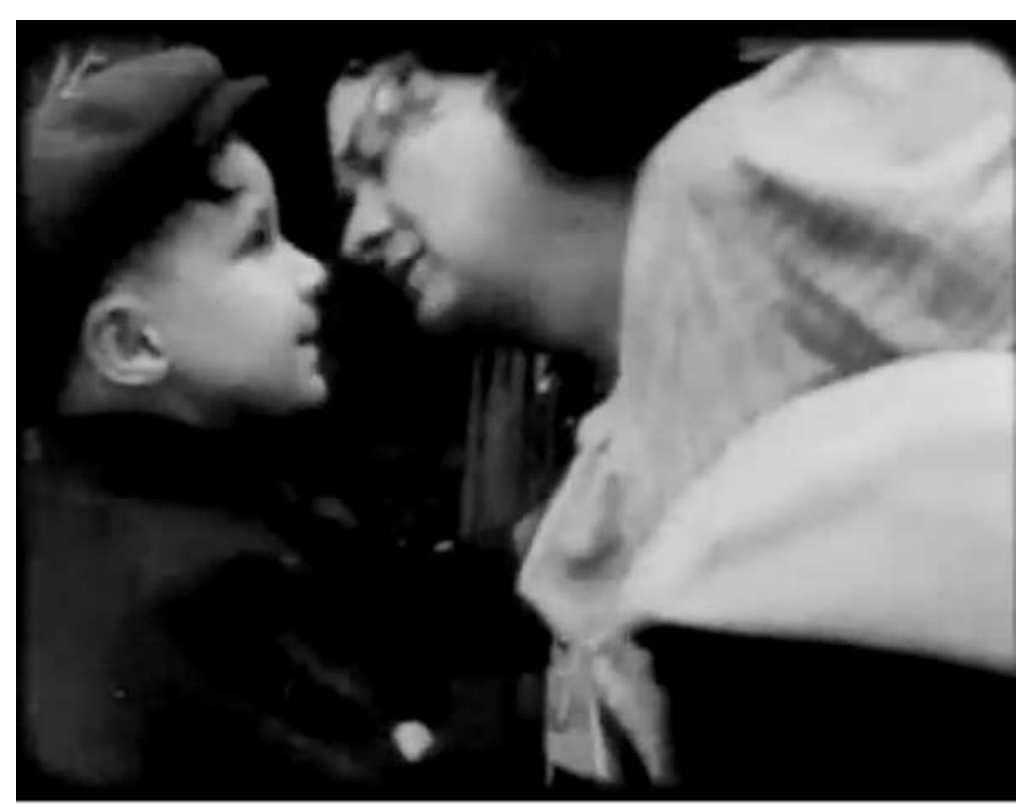

Figura 2 
REVISTA CRIOULA N² $21-1^{\circ}$ SEMESTRE/2018

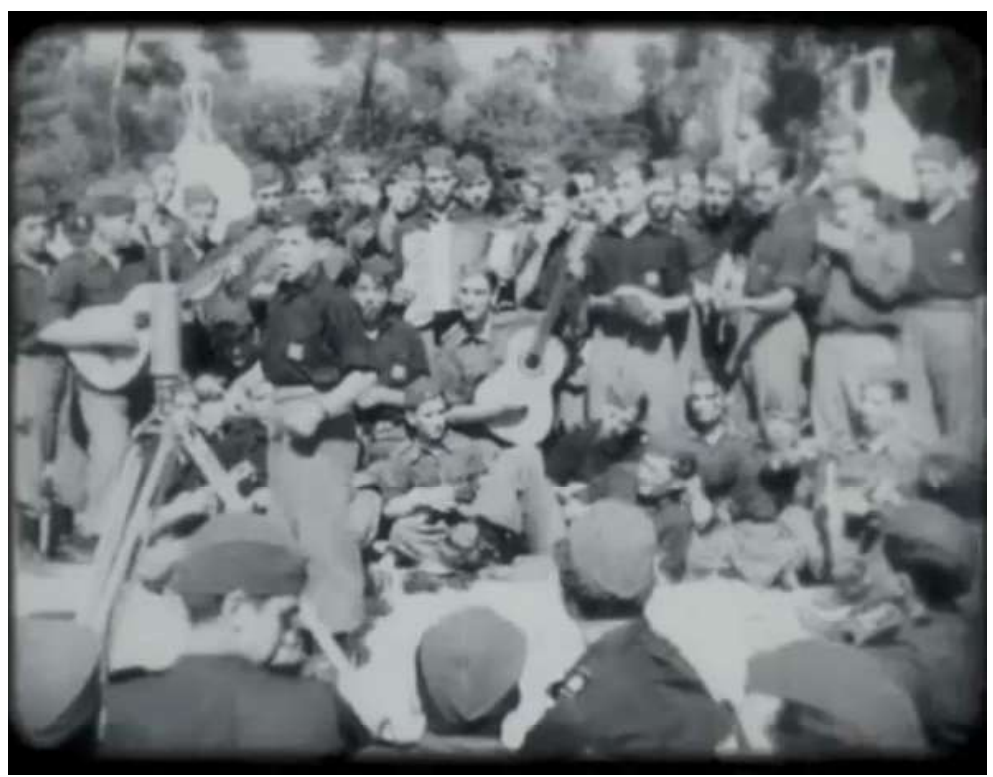

Figura 3

O uso desta técnica de montagem revela que, enquanto a maioria da Europa se debatia com os sofrimentos de origem bélica, Portugal, que se manteve neutro durante todo o conflito, vivia alheio ao que acontecia no restante do continente. Esse insulamento português se deveu ao fato de o governo salazarista priorizar incutir na mente da população valores cívicos e religiosos de seu país, em vez de permitir que notícias do exterior pudessem circular livremente sem os grilhões da censura.

\section{O Portugal SAlazarista VIVIdo PElos REFugiados}

Com relação à Fantasia Lusitana, várias são as passa- 
gens anotadas pelos três refugiados que desmascaram a ideologia salazarista. No entanto, para este artigo, optamos por individualizar apenas um dos âmbitos presentes no testemunho desses intelectuais. Trata-se do estranhamento vivido por eles em relação à iluminação noturna de Lisboa em contraponto à escuridão nas cidades sob ataques de bombardeiros.

É importante contextualizar que os três estrangeiros passaram por Lisboa em 1940, ano das comemorações do Duplo Centenário, ou seja, oito séculos da fundação de Portugal e três séculos de sua restauração. Por esse motivo, o segundo semestre daquele ano abrigou a Exposição do Mundo Português, uma feira em Belém que consistia em diversos pavilhões que exaltavam a nação por meio do viés ideológico do regime, englobando, resumidamente, as figuras históricas do passado, os usos e costumes do povo e o território português de além-mar. Por este motivo, Lisboa mostrava-se mais iluminada do que nunca.

Assim sendo, o clima em Portugal era festivo, havendo pouca empatia para com as vítimas da guerra ou para com os refugiados que ocupavam as ruas da capital. Somava-se a isso o alheamento que os portugueses viviam sob o filtro da censura, tendo acesso apenas às informações que eram controladas pelos órgãos de inspeção. Além do mais, o Secretariado da Propaganda Nacional, criado em 1933 e administrado por António Ferro, difundia uma 


\section{REVISTA CRIOULA N² $21-1^{\circ}$ SEMESTRE/2018}

imagem positiva do país e de seu líder, fazendo com que a população, grosso modo, aprovasse o governo. Vejamos alguns excertos das anotações desses refugiados referentes às luzes de Lisboa:

- Erika Mann:

Eu estranhava quando anoitecia e não escureciam a cidade. Parecia-me pouco natural que ao cair da noite houvesse luzes nas janelas e que acendessem os candeeiros da rua. Era surpreendente para mim que não temessem os bombardeamentos nazis. (FANTASIA LUSITANA, 2010, 43:22-43:48)

- Alfred Döblin:

Não longe daqui a grande nação francesa contorcia-se de dor. Cidades inteiras mergulhadas na obscuridade da guerra. O norte do país inundado de conquistadores. Passava-se fome e aguardavam-se ordens do invasor. Sofria-se e estava-se prostrado. Milhões de homens levados para cativeiro, milhões de pessoas aterrorizadas, dezenas de milhares de mortos - e aqui, em Lisboa as luzes brilhavam. Desfrutava-se a 
paz. Mas nós não conseguíamos sentir alegria. Só pensávamos no que deixamos para trás. Irrequietos, dirigimo-nos de carro para a cidade do brilho, de um brilho que se nos parecia infernal.(FANTASIA LUSITANA, 2010, 21:01-21:48)

- Antoine de Saint-Exupéry:

As cidades na minha terra, à noite, eram cor de cinza. Eu tinha perdido o hábito de ver a luz e esta capital radiosa causava-me uma espécie de mal-estar. Eu sentia pesar sobre Lisboa a noite da Europa habitada por grupos errantes de bombardeiros, como se eles tivessem farejado de longe este tesouro. E por detrás do seu sorriso, Lisboa parecia-me mais triste do que as minhas cidades apagadas. Mas Portugal tentava acreditar na felicidade, com os seus serviços de mesa, os seus candeeiros e a sua música. Brincava-se à felicidade em Lisboa, para Deus poder acreditar. (FANTASIA LUSITANA, 2010, 34:21-35:00)

Apesar de se encontrarem em território neutro, os três refugiados mantêm seus pensamentos nas vítimas da guerra, sentindo tristeza e pesar. O estranhamento vivido 
por eles diante das luzes lisboetas remete-os à escuridão com a qual estavam habituados. Saint-Exupéry chega até mesmo a sugerir que a iluminação de Lisboa poderia atrair a atenção dos nazistas, revelando a fragilidade daquela capital.

\section{CONSIDERAÇÕES FINAIS}

O nosso objetivo com este artigo foi o de mostrar que tanto o romance de Saramago quanto o documentário de Canijo conseguem desconstruir a imagem de um "oásis de paz" português criado pela propaganda do Estado Novo. Por meio de estratégias de narração e de montagem, ambos os suportes revelam duas camadas distintas naquele contexto, isto é, 1-) o mundo português idealizado e construído pela propaganda salazarista e 2-) o mundo bélico, vivido nos outros países europeus.

No romance, o narrador analítico e irônico exerce papel primordial na desconstrução da imagem de Salazar e da propaganda estatal. Além da instância narrativa, personagens críticos, como Fernando Pessoa, contribuem com a desestabilização do status quo instituído após a criação do Estado Novo.

No documentário, o estranhamento vivido por Döblin, Mann e Saint-Exupéry ao se depararem com uma terra estrangeira, influenciada por princípios nacionalistas e corpo- 


\section{REVISTA CRIOULA N ${ }^{\circ} 21$ - $1^{\circ}$ SEMESTRE/2018}

rativistas, faz com que venha à tona a fragilidade portuguesa que o governo lutava por esconder.

\section{REFERÊNCIAS BIBLIOGRÁFICAS}

FANTASIA LUSITANA. Direção de João Canijo. Produção de João Trabulo. Realização de João Canijo. Intérpretes: Hanna Schygulla, Rüdiger Vogler, Christian Patey. Roteiro: João Canijo. Música: Pedro Góis. Lisboa: Periferia Filmes, 2010. 1 DVD (67 min.), son., P\&B. Legendado. Disponível em: $\quad$ https://www.youtube.com/watch?v=cAtTwRnjXyQ. Acesso em: 01 dez. 2017.

ROSAS, Fernando. O salazarismo e o homem novo: ensaio sobre o Estado Novo e a questão do totalitarismo. Análise Social, Lisboa, v. XXXV, p. 1031-1054, 2001.

SARAMAGO, José. O ano da morte de Ricardo Reis. São Paulo: Companhia das Letras, 1994.

SOUSA, Sérgio Paulo Guimarães de. Relações Intersemióticas entre o Cinema e a Literatura: a Adaptação Cinematográfica e a Recepção Literária do Cinema. Braga: Centro de Estudos Humanísticos/Universidade do Minho, 2001.

TORGAL, Luís Reis (Coord.). O Cinema sob o olhar de 
REVISTA CRIOULA N ${ }^{\circ} 21-1^{\circ}$ SEMESTRE/2018

Salazar. Lisboa: Temas e Debates, 2011.

Submissão: 07/02/2018

Aceite: 08/04/2018 